\title{
Francisco Gómez Martos, Historiografía del postmodernismo. Anejos de la Revista de Historiografía, 2 (2014): 150 págs.
}

Hay que agradecer al Instituto de Historiografía Julio Caro Baroja, y a su Revista de Historiografía, que hayan apostado por publicar finalmente una obra que por distintas vicisitudes editoriales no pudo ver la luz en el momento de su redacción en 2009. Como señala la nota editorial que acompaña a este libro, si bien es cierto que un lustro es tiempo suficiente como para afectar a la actualidad de todo trabajo, también lo es que el contenido de este que nos ocupa merecía ser publicado, aunque sea de forma tardía. La historiografía española no anda precisamente sobrada de publicaciones que traten aspectos de tipo teórico o de análisis de contenido crítico sobre distintos problemas historiográficos. Todavía menos sobre una cuestión a menudo tan resbaladiza como es la historiografía postmoderna, y su recepción entre los historiadores españoles, tema por lo demás central de esta obra a pesar de que su título más generalista pueda llamar a confusión en un principio. De hecho, la tesis que plantea Francisco Gómez Martos es que el desarrollo del postmodernismo y sus debates en la historiografía española pueden ser leídos como un claro reflejo de las carencias de esta última. ${ }^{1}$

En relación con esta línea argumental, la estructura de la obra se organiza en torno a dos partes diferenciadas, aunque directamente relacionadas. La primera constituye un análisis de los rasgos intelectuales e institucionales de la historiografía postmoderna, que parte de la idea de que el postmodernismo es un fenómeno esencialmente anglosajón cuyas raíces teóricas se hallan en el pensamiento francés. Por lo tanto, Gómez Martos analiza la aparición del postmodernismo como el resultado de un juego de recepción y acoplamiento; el llevado a cabo entre las teorías del estructuralismo y postestructuralismo francés y el contexto académico estadounidense de los años sesenta y setenta. Solo que en este caso, la adaptación de las ideas de Roland Barthes, Jacques Derrida, Michel Foucault o Jean Braudillard, entre otros, a las características de universidades como Yale, Cornell, Duke o Johns Hopkins, acabó por producir una ruptura radical con la idea de modernidad que afectó a todas las ramas del conocimiento. En este proceso, que dio como resultado la conversión de una noción de postmodernismo propia del arte vanguardista y la literatura en otra que apuntaba a la existencia de una cultura postmoderna dentro las ciencias humanas y sociales, intervinieron factores de tipo político e institucional, según Gómez Martos. Estos se encuentran relacionados con el elitismo de unas universidades interesadas en acentuar sus rasgos distintivos en una época de conflicto social, como demuestra por ejemplo la promoción de la abstracción teórica derridiana desde diferentes estructuras de poder económico, político y académico. Ahora bien, una de las principales claves para entender este proceso, la encontramos en la descripción que hace este autor de cómo las teorías del postestructuralismo francés, de contenido filosófico y construidas con una clara ambición de totalidad, pasaron a convertirse en el ámbito académico norteamericano en un instrumento de la crítica literaria, para desde aquí contagiar a la antropología y desembocar finalmente en una nueva visión sobre la teoría cultural implícita en las ciencias sociales. De esta manera se entiende la importancia que Gómez

\footnotetext{
1 Este autor ha publicado además algún trabajo relacionado específicamente con la reflexión historiográfica española, como Francisco Gómez Martos, "Aproximación a la teoría de la historia: una perspectiva española", Gallaecia, 27 (2008), 313-29.
} 
Martos concede a la crítica literaria como el campo en el que se produjo esta transmutación, el lugar donde la semiótica de Barthes y la deconstrucción de Derrida se transformaron en artefactos de la crítica literaria que comenzaron a entender la literatura como una operación lingüística, sin relación con ninguna realidad objetiva o exterior al lenguaje. Como vemos, de aquí a la consideración tan característica de la historiografía postmoderna de que la historia no puede reflejar la realidad de los hechos del pasado que estudia -en tanto solo es una construcción textual no objetivable-, tan solo hay un paso.

Dentro de este marco general de análisis, la introducción de las técnicas literarias postestructuralistas en los estudios históricos llevada a cabo por la Intellectual History, y por Hayden White y Dominick LaCapra más concretamente, es para Francisco Gómez Martos el factor determinante que explica la aparición de una historiografía postmoderna. De este modo, siguiendo con su análisis, la historiografía quedó afectada del giro hermenéutico e interpretativo liderado por la crítica literaria y la antropología que, favorecido también por el derribo de las fronteras tradicionales entre instituciones y productos culturales característico de los Cultural Studies, configuró un frente común que ponía en tela de juicio la representación como espejo de la realidad, desde el análisis del discurso y del papel de la cultura. Pero no toda la historiografía, claro; interesa recordar aquí, para comprender mejor algunos juicios posteriores, la preocupación de Gómez Martos en señalar que hasta los años 90, la popularidad de la historiografía postmoderna liderada por White y LaCapra fue mayor entre la crítica literaria que entre los historiadores, y apenas existente fuera de la historia intelectual o de instituciones como las Universidades de Cornell y la Johns Hopkins. De ahí que finalmente, como hacen la mayoría de estudios que han intentado acercarse a este problema, Gómez Martos termine por hacer referencia al cruce de intereses entre la Intellectual History y las teorías literarias, que acabaría por dar lugar a dos ramas diferentes de la disciplina en un momento de crisis de la misma en los años setenta: una abierta a la historia social y a la influencia de otras ciencias sociales; y una segunda que defendía una historia intelectual emancipada a partir de criterios lingüísticos. Dentro de esta última, echaría a andar una historiografía postmoderna centrada en el estudio de la literatura, la historia de las ideas y la teoría de la historia, sobre todo después del célebre congreso celebrado en Cornell en 1980.

La siguiente preocupación de Gómez Martos es la de qué ha podido suceder para que la historiografía postmoderna haya pasado de este reducto minoritario de 1980, al mayor impacto de sus postulados constatable a principios del siglo XXI. En este punto este autor ofrece una atractiva idea de partida: la evolución de la historiografía postmoderna en este lapso de tiempo es indisociable de los cambios ocurridos en el terreno de la historia y las ciencias sociales. O dicho de otro modo: no se puede comprender el desarrollo postmoderno por sí mismo -lo cual en definitiva quiere decir desde una perspectiva postmoderna, no lo olvidemos-, sino que hay que tener en cuenta el desarrollo de la nueva historia cultural, con la que a pesar de las notables diferencias que las separan comparte un frente común de cara a la historia anterior, y lo que es más importante todavía, una mismas circunstancias históricas. Ahora bien, también es cierto que el problema de las relaciones entre dichas variables es difícil de abarcar, y suscita muchas cuestiones. El propio Gómez Martos, tras subrayar estas ideas, no acaba de encontrar una clara respuesta al problema, y termina por describir algunos rasgos de la 
historia cultural llevada a cabo en Estados Unidos y Francia entre los años setenta y comienzos del siglo XXI.

Desde nuestro punto de vista, posee mayor relevancia su análisis final sobre la historia postsocial británica, o historia postmarxista, entendida esta como la historiografía posterior al apogeo de la historia social. De hecho, este caso le brinda a Gómez Martos la oportunidad de ilustrar cómo la recepción del postmodernismo en Gran Bretaña se produjo dentro del "giro cultural" producido en el seno de su historia social, y para adelantar algunas de sus posiciones respecto al postmodernismo sobre las que incidirá más adelante. Sin ir más lejos, sobre el problema del lenguaje - o la contraposición entre una visión que lo considera como parte de la realidad y aquella de cariz postmoderno que ve la realidad definida por el lenguaje-, Gómez Martos observa el inconveniente de una historiografía conducida por un círculo vicioso de subjetividad que mezcla los problemas del acceso al pasado con el pasado mismo y sustituye los hechos por la lengua. Ahora bien, la parte central de su exposición sobre la historia postsocial está dirigida a mostrar el proceso de transformación de la historiografía británica desde un marxismo renovado culturalmente, que condujo a cuestionar los planteamientos de la historia social anterior. Siguiendo con esta interpretación, Gómez Martos describe cómo fue precisamente en este contexto donde se comenzaron a dar los primeros pasos del giro lingüístico a partir de los años 80, entendido todavía como una manifestación más de la nueva historia cultural de estos años, hasta que a partir de 1989 se empieza a expandir un postmodernismo comparable al estadounidense. Dicha expansión dará a esta corriente un nuevo viraje subjetivo e idealista más radical de la mano de lo que califica como "postmodernismo chichesteriano", el protagonizado por autores como Alun Munslow y Keith Jenkins en la Universidad de Chichester.

Este repaso inicial por los orígenes y desarrollo de la historiografía postmoderna, si bien recoge cuestiones más o menos conocidas entre los especialistas, constituye una buena síntesis sobre este problema. Nos emplaza asimismo ante la paradoja de que a la hora de acercarnos y comprender este fenómeno, resulta más útil una aproximación de tipo contextual que los análisis de tipo discursivo realizados desde la propia retórica postmodernista. Sin embargo, el objetivo de este primer bloque es el de presentar un análisis sobre la historiografía postmoderna que sirva para enmarcar el que es en definitiva el problema central de este trabajo: la relación de la historiografía española y el postmodernismo. Según Gómez Martos además, este tema lleva aparejado una serie de tópicos y lugares comunes que es preciso volver a considerar; como la idea de que la recepción del postmodernismo en España ha sido tardía y ha tenido un débil impacto. Por el contrario, y en discrepancia sobre todo con la opinión de Miguel Ángel Cabrera, para Gómez Martos el caso español es similar en términos comparativos a lo acaecido en otros países, donde el postmodernismo ha sido más cuestionado que aplicado, y no comenzó a ser ampliamente difundido hasta los años $90{ }^{2}$ Asimismo, según Gómez Martos la obra de White, los postulados del giro lingüístico, la historia postsocial y postcolonial, etc., han sido conocidos en España en el tiempo que transcurre desde principios de los años noventa hasta la primera década del siglo XXI. Ahora bien, ello no quiere decir para él que exista una historiografía postmoderna en España; su calado no pasa de una serie de figuras individuales sin continuidad, o de algún centro como el

\footnotetext{
${ }^{2}$ El artículo donde Cabrera trata estos aspectos: Miguel Ángel Cabrera, "El debate postmoderno sobre el conocimiento histórico y su repercusión en España”, Historia Social, 50 (2004), 141-64.
} 
de La Laguna en torno a Miguel Ángel Cabrera, y no ha llegado nunca a conquistar núcleos duros de la historiografía española -como demostraría para él el caso de la revista Historia Social, que a pesar de ser el organismo donde se han traducido los principales trabajos de la historiografía postmoderna, es deudora de la historia social más clásica-.

Pero para Gómez Martos, el postmodernismo se encuentra presente en la historiografía española, aunque solo sea a través de una actitud de escepticismo como dijera Juan Sisinio Pérez Garzón. No constituye una alternativa, pero sí que ha comenzado a producir algunos frutos y debates, bien en forma de intentos por renovar la historiografía, bien para huir radicalmente de ella. El problema para este autor, y aquí viene la tesis central de esta obra, es que las carencias de la historiografía española han impedido que este debate haya sido contrastado, algo que Gómez Martos considera indispensable, máxime cuando debajo de las distintas posturas existentes se esconden cuestiones absolutamente irreconciliables. Merece la pena detenerse en algunas de estas carencias que apunta Gómez Martos como limitadoras del debate postmoderno en España. Primero de todo, la tantas veces lamentada falta de escuelas metodológicas y debates teóricos entre la historiografía española, que convierte toda reflexión metodológica o historiográfica en un ejercicio individual que solo desemboca en asociaciones o grupos más amplios por la vía del clientelismo académico o las afinidades personales. De este modo, continúa Gómez Martos, cuando los historiadores españoles reflexionan sobre su disciplina a título individual o grupal, "construyen su propio feudo sin contrastar sus argumentos con los de los demás colegas" (p. 75). Ello es especialmente palpable, continúa el autor, en la política de los congresos, caracterizados por su gran disparidad sin capacidad de ofrecer síntesis o perspectivas generales; en la publicación de obras de recopilación de trabajos de un mismo autor sin ningún tipo de perspectiva ni eje común; o en la aparición de libros de recopilación de artículos sin tener ideas de conjunto, y ni siquiera relación con el mismo título. Por último, Gómez Martos echa en falta también la ausencia de debates que pongan de manifiesto las similitudes, contradicciones o tensiones entre los autores de referencia para el conocimiento historiográfico en España, como puedan ser Josep Fontana y José Carlos Bermejo.

En virtud de estas reflexiones anteriores, Gómez Martos adopta a partir de este momento una actitud crítica, en cierto modo combativa, que defiende la necesidad que tiene la historiografía española por poner de manifiesto las contradicciones existentes entre su propia reflexión historiográfica. Esta es para el autor la única verdadera vía posible para llevar a cabo un auténtico avance historiográfico que huya de la mera acumulación de estudios de consenso sin ningún tipo de confrontación. Y todavía más en lo que respecta al postmodernismo, en cuanto que las propuestas de un autor como Miguel Ángel Cabrera, sin ir más lejos, se presentan esencialmente incompatibles con la mayoría de los historiadores españoles. En este sentido, esta segunda parte de la obra es en definitiva un intento de llevar a cabo este propósito, o por lo menos de plantear un debate crítico no solo con las premisas teóricas de signo postmoderno, sino también con algunas de las reflexiones historiográficas aparecidas en la historiografía española de la primera década del siglo XXI, a través de autores representativos para Gómez Martos del debate sobre el postmodernismo en España como Miguel Ángel Cabrera, Julio Aróstegui, Elena Hernández Sandoica, Jaume Aurell, Carlos Barros e Historia a Debate y José Carlos Bermejo. 
El primer autor en ser tratado, obviamente, es Miguel Ángel Cabrera, en su papel de principal representante del postmodernismo en España y quien ha sentado los puntos de referencia para el debate. De ahí que Gómez Martos parta de algunas de las ideas generales transmitidas por Cabrera sobre lo que es la historiografia postmoderna, con el objetivo de establecer una clara posición inicial acerca de sus postulados. Comenzando además con una crítica frontal al exclusivismo del que hace gala Cabrera al ceñirse solo a los autores postmodernos, y defender una radical ruptura con la tradición historiográfica $-\mathrm{O}$ con la modernidad si se quiere-, donde tan solo son tenidos en cuenta aquellos que comprenden la importancia de la construcción significativa de los objetos de estudio a través de la mediación lingüística. Por el contrario, para Gómez Martos este hecho supone una clara limitación del conocimiento. La crítica al postmodernismo, continúa, no solo es posible desde otras posiciones, sino necesaria, en cuanto que sus propuestas afectan al conjunto del trabajo historiográfico. De ahí que este autor acabe por recoger también una de las críticas corrientes realizadas al postmodernismo, tras recordar cómo Cabrera presenta el debate postmoderno tan solo en términos epistemológicos, de una manera en la que tan solo existe texto, historiador y mediación lingüística entre ellos. Dicha crítica señala que al incidir en la mediación entre historiador y pasado, esta mediación se convierte en una teoría finalista que acaba por sumir al historiador en un "escepticismo radical" que dificulta la utilidad de la teoría histórica, y convierte a los hechos en algo ininteligible.

Una vez establecida de forma clara su posición, y consciente de que la historiografía española no ha llegado a caer en estos extremos anteriores, Gómez Martos se detiene en otros tipos de acercamiento al postmodernismo entre los historiadores españoles. Dos ejemplos casi paralelos, y muy relacionados, los encuentra en la obra teórica e historiográfica de Julio Aróstegui y Elena Hernández Sandoica. En cuanto a Julio Aróstegui, Gómez Martos valora su temprano conocimiento a principios de los años 90 del postmodernismo, y su comprensión de la originalidad de la obra de White dentro del complejo panorama postmoderno y el contexto de su tiempo, para a partir de 1995, y sobre todo ya en la segunda edición de La investigación histórica, atacar ya sin ambages la irracionalidad y las modas narrativas y postmodernas. ${ }^{3}$ Sin embargo, no se muestra tan complaciente Gómez Martos con la obra que Aróstegui dedicó a la historia del tiempo presente, y que considera relacionada con el postmodernismo en tanto que fenómeno histórico. En este caso, y siguiendo especialmente algunas posiciones de José Carlos Bermejo, considera que el planteamiento de Aróstegui es similar a otras corrientes de tipo ahistórico, y en cierta medida opuesto a sus mismas propuestas teóricas, al convertir la globalización, internet, o los medios de comunicación, en premisas explicativas de una propuesta de historia global centrada en la cultura del tiempo vivido. ${ }^{4}$ Algo similar ocurre con la obra historiográfica de Hernández Sandoica, que Gómez Martos elogia por constituir una radiografía intelectual de los cambios producidos en la historiografía reciente. Así, en un primer momento Gómez Martos destaca la capacidad de esta autora para comprender los conceptos historiográficos actuales, y para desentrañar los complejos giros y tendencias producidos en la

\footnotetext{
${ }^{3}$ Julio Aróstegui, La investigación histórica: teoría y método (Barcelona: Crítica, 1995 y 2001).

${ }^{4}$ J. Aróstegui, La historia vivida. Sobre la historia del presente (Madrid: Alianza, 2004).
} 
historiografía. $^{5}$ Pero a continuación, critica finalmente su propuesta historiográfica agrupada bajo la etiqueta de "nuevo historicismo", por imprecisa, y por desembocar en un "idealismo historicista" que aplica indiscriminadamente este concepto global sobre una historiografía muy compleja. Y cuestiona también que siguiendo los postulados de Lynn Hunt, Hernández Sandoica acepte como buena la idea de que la historiografía se encuentra en una situación de stand by caracterizada por la falta de un estatuto epistemológico definido tras la crisis de los grandes paradigmas, que por lo tanto reduce su sentido a una práctica ética y política. Y todo esto sin tener en cuenta además las reflexiones sobre la relación entre historia y sus aspectos éticos realizadas por José Carlos Bermejo, que Gómez Martos acaba achacando a la dificultad que supone que grandes especialistas en estas cuestiones -como Bermejo, Hernández Sandoica, o Fontana- ocupen puestos de poder en distintas editoriales o colecciones.

Menor crédito suscita todavía a Gómez Martos la obra historiográfica tanto de Jaume Aurell como de Carlos Barros en Historia a debate, representativas para él de esta valoración en términos de impasse de la historiografía actual, y de la búsqueda de vías de renovación basadas en "terceras vías" o consensos -cuando para él no hay necesidad de mostrar una historiografía armónica y tolerante cuando se presentan muchas veces conceptos irreconciliables entre sí mismos-. Un ejemplo de tercera vía lo halla en Jaume Aurell y La escritura de la memoria. ${ }^{6}$ Dicha obra nos es presentada como un cúmulo de despropósitos desde el mismo título. Para Gómez Martos este libro no solo está escrito desde una visión esquemática de la historia de la historiografía, y por lo tanto simplista y plagada de tópicos -que subordina su progreso a la novedad sin relacionar los textos con los contextos en los que se producen-, sino que además plantea una tercera vía entre positivismo y el escepticismo postmoderno como una síntesis entre dos planteamientos que Aurell ha construido a fuerza de simplificar, para después reivindicar el relato histórico como objetivo para poder llegar a un público más amplio. Asimismo, Gómez Martos incide en este mismo tono crítico cuando se acerca a Carlos Barros y los proyectos desarrollados desde Historia a Debate. En cierto modo, aunque se pueda estar de acuerdo con sus argumentos, sorprende la elección de este autor y proyecto en relación con el tema de esta obra, cuando el mismo Gómez Martos declara que su aproximación al postmodernismo ha sido muy vaga, o que su aportación al progreso historiográfico ha sido escasa. Con todo, el grueso de sus críticas van dirigidas al uso indiscriminado y poco fiable del concepto de paradigma de Carlos Barros, edificado también sobre una visión simplista de la evolución historiográfica, y a la noción de consenso historiográfico manejada por este colectivo. Para Gómez por el contrario, las contradicciones acumuladas por la historiografía del siglo XX hacen imposible una vía de renovación basada en el consenso, y es más necesario cuestionar conceptos, consensos, paradigmas y desmontar con argumentos sólidos sus funciones ideológicas.

Por último, esta obra de Gómez Martos termina contrastando dos propuestas teóricas que son representativas de diferentes formas de comprensión de la historiografía postmoderna. La primera, es el ensayo de historia postsocial efectuado

\footnotetext{
5 Se refiere aquí especialmente a Elena Hernández Sandoica, Tendencias historiográficas actuales. Escribir historia hoy (Madrid: Akal, 2004).

6 Jaume Aurell, La escritura de la memoria. De los positivismos a los postmodernismos (Valencia: Publicaciones de la Universidad de Valencia, 2005).
} 
por Miguel Ángel Cabrera a comienzos del siglo XXI a partir de su Historia, lenguaje y teoría de la sociedad. ${ }^{7}$ No es necesario señalar a estas alturas que Gómez Martos básicamente discute los postulados de Cabrera, al considerar esta obra como un intento de formulación de historia postsocial que queda en un ejercicio de debate teórico efectuado desde el giro lingüístico, en el que ni el espacio ni el tiempo parecen tener importancia. Pero es que además es ahora cuando nos encontramos una respuesta más definida por parte de Gómez Martos a las tesis de Cabrera -y a las de su compañero Álvaro A. Santana-. Así, tras señalar cómo este paradigma de historia postsocial se presenta como una alternativa para reemplazar a una historia objetivista, más concretamente a una historia social que agrupa bajo el paraguas del materialismo sin hacer distinciones, y cómo Cabrera defiende una historia que se limita a hacer una historia del concepto de lo social, nos dice:

\begin{abstract}
La transformación del utillaje conceptual es inherente al trabajo del historiador, y el concepto de sociedad, como cualquier otro, es también susceptible de ser sometido a revisión. Pero esa revisión no necesariamente tiene que llevar a su desprecio, entre otras cosas porque el lenguaje y los conceptos forman parte de la realidad, presente y pasada, porque no hay otra forma -entre las racionales- de conocer el pasado sino a partir de su categorización conceptual [...], porque de la supuesta relación que existe entre su uso y un "imaginario moderno" no se deduce su inoperancia, y finalmente porque Cabrera y Santana no nos proponen otras formas de concebir la interacción humana, ni siquiera se nos incita a buscarlas, ya que su objeto de estudio no parece ser la historia de la sociedad o la sociedad misma, sino la reflexión sobre ésta al margen de su existencia real (p. 121).
\end{abstract}

De tal modo, para Gómez Martos esta teoría de Cabrera solo conduce a vaciar de significado la tradición historiográfica, lo cual tendría además graves consecuencias, ya que aunque pueda contener ideas interesantes:

[...] la teoría que las sostiene y los términos en que se formulan, más que el radicalismo, rozan lo dogmático y constriñen el espíritu crítico, anquilosando la teoría al extremo de que no pueda ser verificada empíricamente sino solo a través de la deconstrucción y haciendo del discurso y del lenguaje los únicos medios por los que aprender y explicar la realidad histórica, hasta reducirlo a un ejercicio de especulación retórica lejos del espíritu que caracteriza y necesita el historiador (p. 124).

Por el contrario, Francisco Gómez Martos considera que ha sido José Carlos Bermejo quien mejor ha sabido leer el postmodernismo, puesto que su obra epistemológica plantea con más realidad este fenómeno por dos razones: posee una mayor conocimiento del contexto en que se desarrolla el postmodernismo, y no lo considera una alternativa, sino una forma distinta de abordar el conocimiento que debe ser valorada como tal. Además, Bermejo sí que intentaría llevar al límite las contradicciones inherentes al postmodernismo, una reclamación constante de Gómez Martos en esta segunda parte la obra como sabemos. En consecuencia, indica, Bermejo considera en su historia teórica que la versión más elaborada del postmodernismo, aquella que se basa en la teoría del relato y la narratividad, es insuficiente, si bien interesante siempre que no se utilice como instrumento y se olvide que es necesario acudir a un contexto histórico, social o político más amplio. ${ }^{8}$ Esta idea además lleva a

\footnotetext{
${ }^{7}$ Miguel Ángel Cabrera, Historia, lenguaje y teoría de la sociedad (Madrid: Frónesis, 2001). Esta obra fue además traducida al inglés como Postsocial History: An Introduction (Lanham: Lexintong Books, 2005).

${ }^{8}$ José Carlos Bermejo cuenta ya con una amplia, dilatada y original obra dedicada el pensamiento historiográfico que sería imposible de detallar aquí. A modo de ejemplo, dos obras relacionadas con su
} 
Gómez Martos a advertir otra diferencia entre Bermejo y Cabrera; si este último básicamente analiza el papel del lenguaje en la construcción de significados, no presta atención en cambio a la narrativa o a una visión del postmodernismo en cuanto que teoría de la escritura o filosofía narrativa que Bermejo por el contrario sí que percibe, puesto que considera que la vigencia de la narratividad, sea postmoderna o no, es una consecuencia de un mundo dominado por la imagen que ha renunciado a un pensamiento filosófico fuerte. Sin embargo, de ser esto así, resulta curioso que el propio Gómez Martos no haya dedicado mayor atención al problema de la relación entre la teoría del relato y el postmodernismo en la primera parte de la obra.

Como decíamos al principio de esta reseña, es de agradecer que esta Historiografía del postmodernismo haya sido finalmente publicada. Primero por el tono desenfadado y crítico de la obra, polémico en ocasiones, que busca claramente suscitar debates de forma pensamos que valiente, aunque mucho nos tememos que este objetivo no obtenga respuesta, o si la tiene, sea de carácter más despectivo que argumentativo. Es cierto que su publicación con cinco años de retraso tampoco ayuda a la hora de fomentar este debate, debido a la pérdida de potencia de algunos de los textos y cuestiones a las que se refiere Gómez Martos. En relación con este hecho, es irremediable plantearse qué ha sucedido desde su redacción en 2009 con respecto a los problemas que plantea. Probablemente no mucho, más allá de la aparición algunas publicaciones de signo postmoderno o estudios sobre la historiografía postmoderna que podamos encontrar. ${ }^{9}$ Lo cual nos lleva a otra pregunta estrechamente relacionada: ¿es la historiografía postmoderna una buena vía para acercarse al análisis de la historiografía española y su reflexión historiográfica? Desde nuestro punto de vista, quizás sea necesario relacionar este diagnóstico de Gómez Martos con las transformaciones ocurridas en la historiografía española desde comienzos de los años noventa, teniendo en cuenta también su contexto sociopolítico, académico e intelectual, las herencias recibidas y sus problemáticas, como él mismo ha esbozado en el caso de la historiografía británica. Mientras tanto, esta publicación de Francisco Gómez Martos puede ser leída como un buen ensayo sobre el problema de la recepción del postmodernismo en España, que podemos inscribir además dentro de la reacción contra el postmodernismo que se viene produciendo en las ciencias humanas y sociales desde la última gran crisis económica producida en el ámbito occidental.

Óscar Adell Ralfas

Universidad de Zaragoza

oadellralfas@gmail.com

concepto de historia teórica tenidas en cuenta en este libro que reseñamos, José Carlos Bermejo, ¿Qué es la historia teórica? (Madrid: Akal, 2004), e Introducción a la historia teórica (Madrid: Akal, 2009).

${ }^{9}$ Sin ánimo de ser exhaustivos, un ejemplo publicado en esta misma revista se halla en Miguel Ángel Sanz Loroño, "Cuatro caras de Metahistory y una propuesta de interpretación”, Historiografías, 9 (2015): 44-64. 
Fecha de recepción: 2 de diciembre de 2016.

Fecha de aceptación: 16 de diciembre de 2016.

Publicación: 31 de diciembre de 2016.

Para citar este artículo: Óscar Adell Ralfas, "Francisco Gómez Martos, Historiografía del postmodernismo. Anejos de la Revista de Historiografía, 2 (2014): 150 págs.”, Historiografías, 12 (junio-diciembre, 2016): pp. 170-178.

http://www.unizar.es/historiografias/historiografias/numeros/12/adell.pdf 